\title{
When are doctors legally obliged to stop and render assistance to injured persons at road accidents?
}

\author{
D J McQuoid-Mason, BComm, LLB, LLM, PhD \\ Centre for Socio-Legal Studies, University of KwaZulu-Natal, Durban, South Africa
}

Corresponding author: D J McQuoid-Mason (mcquoidm@ukzn.ac.za)

Unlike the USA, South Africa (SA) does not have 'Good Samaritan' laws that oblige doctors to stop at road accidents. In SA, the conduct of doctors in such situations is governed by the common law. Doctors coming across injured people at a road accident should stop and render assistance, unless they are likely to be exposed to personal danger or injury, they are mentally or physically incapable of assisting, or other medical or paramedical practitioners are at the scene. Where there is the threat of personal danger to the doctor, they must immediately report the accident to the police, advise the police to send protection and call for urgent ambulance assistance. Doctors should remain in a safe place near the scene until the police and ambulance arrive and check that paramedics are available to stabilise the injured before departing. Where there is the threat of danger, if doctors are mentally or physically unable to assist or if other medical or paramedical practitioners are at the scene, doctors may or may not be required to stop.

S Afr Med J 2016;106(6):575-577. DOI:10.7196/SAMJ.2016v106i6.10503

Most states in the USA have 'Good Samaritan' laws that oblige doctors to stop and render emergency treatment under certain circumstances, without incurring legal liability even if they are negligent. ${ }^{[1]}$ South Africa (SA) has no such laws, and the duty of doctors to assist at road accidents is governed by the common law. The question arises whether doctors in SA are legally required to stop and render assistance to injured people at road accidents. When there is a public announcement calling for a doctor in situations such as during a movie, doctors usually have no difficulty in responding. When it comes to road accidents, it seems that doctors are more reluctant to stop and render assistance, particularly when they feel that they may be exposed to danger. In order to answer the question whether doctors are legally obliged to stop and render assistance at road accidents under the common law, it is necessary to consider the following: (i) When is there a general legal duty on people to act? (ii) When are doctors legally required to render assistance to injured persons at road accidents? (iii) What standard of care is expected of doctors who render assistance at road accidents? and (iv) When are doctors not legally required to render assistance at road accidents?

\section{When is there a legall duty to act?}

As a general rule in SA there is no legal duty to act unless the law imposes a legal duty to do so. ${ }^{[2]}$ Traditionally the law imposed a legal duty to act in situations, inter alia, where a person has a special relationship with another person or a statute imposes a legal duty to act. ${ }^{[3]}$ These situations were regarded as useful indicators, but were replaced by a more general boni mores (good morals) approach based on the 'legal convictions of the

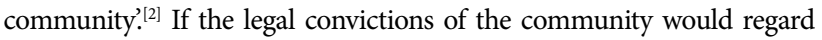
the omission as wrongful, the law would impose legal liability on the person concerned ${ }^{[2]}$ With the advent of the Constitution, the courts have tended to impose liability for failure to act according to the values in the Constitution, rather than the legal convictions of the community. ${ }^{[4]}$

\section{When are doctors legally required to render assistance to injured persons at motor accidents?}

Doctors should offer assistance where people who are not their patients require medical assistance. This applies to situations where their safety is not threatened and where they can render first aid to stabilise patients until they can be handed over to other healthcare practitioners. ${ }^{[5]}$ This often occurs in non-controversial situations when doctors in cinemas or theatres or travelling as passengers in aircraft respond to calls for medical assistance.

\section{Ethical considerations}

In 1978, the SA Medical and Dental Council ruled that that in cases of emergency a practitioner is obliged to render assistance in all circumstances', and it was suggested that this could be 'interpreted broadly to mean that a doctor may not deliberately ignore an emergency situation such as a road accident. ${ }^{[5]}$ It has therefore been said that 'where persons are in a situation where their life or health will be seriously endangered unless they receive immediate medical treatment, a practitioner who is available may not ethically refuse to attend such patients unless there are compelling circumstances that prevent the doctor from acting. ${ }^{[6]}$ In Australia, a Medical Board tribunal found a doctor guilty of improper and unprofessional conduct for failing to stop at an accident and instead driving to the police station to report it. ${ }^{[7]}$ The tribunal found that the doctor's conduct was unprofessional because she failed to stop without checking on the occupants of the car in question to determine whether there were any injuries and whether she could help. If she could not have helped, she should have ascertained the extent and nature of the injuries so that they could be reported to the emergency services. The tribunal stated: 'It matters not that there is no existing professional relationship between a medical practitioner and the persons involved in the accident. ${ }^{\text {[?] }}$

In the UK, 'off-duty doctors are not legally obliged to offer assistance if they come upon a medical emergency, but a failure to assist in an emergency might prompt disciplinary action by the General Medical Council. ${ }^{[8]}$ The Council guidelines state: 'In an emergency, wherever it may arise, you must offer assistance, taking account of your own safety, your competence, and the availability of other options for care. ${ }^{\left[{ }^{[}\right]}$Although the ethical rules of the medical profession are not binding on the courts, the courts may often find such rules useful in determining whether or not a doctor has acted reasonably by not stopping at a road accident. 


\section{Legal considerations}

Unlike SA, the UK does not have constitutional provision that states that nobody may be refused emergency medical treatment. ${ }^{[9]}$ The decision of the SA courts regarding the wrongfulness of the doctor's conduct will be based on the values in the Constitution. ${ }^{[4]}$ Both the Constitution $^{[9]}$ and the National Health $\mathrm{Act}^{[10]}$ provide that nobody shall be refused emergency medical treatment. It is submitted that the right not to be refused emergency medical treatment in the constitution can be interpreted to include providing medical assistance at road accident scenes even when a doctor has not been requested to provide it. A doctor is still obliged to stop and render emergency medical treatment where no other medically qualified person is available, where there is no threat to the doctor's personal safety, and when the doctor is mentally and physically able to assist. This is because persons injured in road accidents are clearly envisaged as the type of individuals that the provision in the Constitution seeks to protect. The Constitutional Court has defined 'emergency medical treatment' as occurring where a person 'suffers a sudden catastrophe that calls for immediate medical attention, ${ }^{[11]}$ which clearly applies to injured road accident victims.

The traditional indicators for when there is a duty to act and the boni mores approaches to actionable omissions may also be used to underpin the values in the Constitution. For example, it could be argued that doctors who come across a road accident involving injured people, who may die or suffer permanent serious injury if they are not provided with immediate medical attention, have a 'special relationship' with injured people in emergency situations even if they are not their patients. ${ }^{[7]}$ In this regard, the Australian Medical Board Tribunal has observed that 'saving human life and healing sick and injured people is a core purpose and ethic of the medical profession. ${ }^{[7]}$ Furthermore, 'a medical practitioner's conduct may be "in pursuit of the practitioner's profession" even where it does not occur in the carrying out of medical practice, provided there is a sufficiently close link or nexus between the conduct and the profession of medicine'. Such a close link exists where a doctor comes across a road accident where there are injured people who require immediate medical assistance. ${ }^{[7]}$ In terms of the 'legal convictions of the community' boni mores approach, ${ }^{[2]}$ it could be argued that the legal convictions of the community would be 'outraged' if a doctor, who is not in any danger and has the capacity to render assistance and save lives, drives past a road accident scene without checking that the injured are being attended to medically. ${ }^{[7]}$

Prior to the present Constitution, it was suggested that in determining whether or not a doctor ought to have rendered assistance in emergency situations, the courts should take into account, inter alia, the following: $(i)$ the doctor's actual knowledge of the patient's condition; (ii) the seriousness of the patient's condition; (iii) the professional ability of the doctor to do what is asked; (iv) the physical state of the doctor (e.g. the doctor may be physically exhausted); $(v)$ the availability of other doctors, nurses or paramedics; and (vi) considerations of professional ethics. ${ }^{\text {[5] }}$ To these must now be added the provision in the Constitution stating that nobody may be refused emergency medical treatment. ${ }^{\left[{ }^{[]}\right.}$The above factors apply generally to emergency situations where doctors are requested to assist, and it is submitted can apply equally to situations where doctors come across road accidents.

\section{What standard of care is expected of doctors who render assistance at road accidents?}

The Health Professions Council of South Africa's rules of professional conduct state that except in emergencies, practitioners shall only perform professional acts for which they are 'adequately educated, trained and sufficiently experienced' and 'under proper conditions and in appropriate surroundings'. ${ }^{[12]}$ Road accidents clearly give rise to emergencies in which doctors are not able to work 'under proper conditions' and 'in appropriate surroundings'.

In emergency situations, the courts will judge the doctor's conduct by how a reasonably competent practitioner faced with similar situation would have acted. In cases of emergencies the same degree of care and skill that is used in a hospital situation may not be required, depending on the circumstances. ${ }^{[13]}$ For instance, the English courts have observed that ' $[\mathrm{a}] \mathrm{n}$ emergency may overburden resources, and, if an individual is forced by circumstances to do too many things at once, the fact that he does one of them incorrectly should not lightly be taken as negligence. ${ }^{[14]}$ It is likely that the SA courts would adopt a similar approach.

\section{When are doctors not legally required to render assistance at road accidents?} The list is not exhaustive, but doctors are not legally required to render assistance at road accidents, for example, when there is a threat to the doctor's personal safety, the doctor is mentally or physically incapable of rendering assistance, or other medical or paramedical practitioners are already at the scene of the accident. Even then doctors may not always simply drive past and do nothing - it depends on the particular circumstances.

\section{Threat to the doctor's safety}

The threat to the doctor's safety must be real rather than apparent, for example a hostile crowd of onlookers or a place notorious for car hijacking. Even in such circumstances the doctor must do something if no medical assistance is present at the scene. He or she may not simply drive past. The doctor should call the police and advise them to send protection and call for urgent ambulance assistance. The doctor should remain near the scene in a safe place until the police arrive. After the arrival of the police, if an ambulance is not yet on the scene, the doctor should assist to stabilise patients until the emergency services arrive to take over. Even though the doctor does not have a trauma kit available, he or she should render basic first aid personally and if necessary direct the police or onlookers on how to assist using triage. Once an ambulance arrives, the doctor should check that paramedics are able to stabilise the injured before departing.

\section{Doctor mentally or physically incapable of rendering assistance}

Doctors may not be in a fit state to assist injured persons at accident scenes if they are mentally or physically incapable of rendering assistance, for example if intoxicated or physically exhausted while being driven in a third party's vehicle. In such situations - provided the doctors are mentally capable of making such requests - they should ask the persons accompanying them to call the police. If doctors are not mentally capable of making such requests, they cannot be held legally liable for failing to act.

\section{Other medical or paramedical practitioners present}

Where other medical or paramedical practitioners are at the road accident scene, it is not necessary for doctors to stop and render assistance, depending on the circumstances. If, for example, it appears that the emergency services are coping with the situation, it is not necessary to stop. If it is clear that large numbers of injured people are involved and the attending practitioners may be overwhelmed, doctors should stop and inquire whether the victims need assistance. 


\section{Conclusions}

Generally, doctors who are the first to come across injured people at a road accident should stop and render assistance unless they may be exposed to personal danger or injury if they stop, are mentally or physically incapable of rendering assistance, or other medical or paramedical practitioners are already present. Where there is the threat of personal danger to the doctors they must immediately report the accident to the police and advise them to send protection and call for urgent ambulance assistance. They should remain near the scene until the police and ambulance arrive and check that paramedics are available to stabilise the injured before departing. Where there is the threat of danger, doctors are mentally or physically unable to assist or other medical or paramedical practitioners are at the scene, doctors may or may not be required to stop - depending on the circumstances.
1. Boumil MM, Elias CE. The Law of Medical Liability. St. Paul, Minn.: West Publishing Co, 1995:146-151 2. Minister van Polisie v. Ewels 19753 SA 590 (A).

3. Neethling J, Potgieter JM, Visser PJ. Law of Delict. 4th ed. Durban: Butterworths, 2001:69,73. 4. Cf. S v Makwanyane 1995 (3) SA 391 (CC).

5. Strauss SA. Doctor, Patient and the Law. 4th ed. Pretoria: IL van Schaik, 1991:25.

6. McQuoid-Mason DJ. The medical profession and medical practice. In: Joubert WA, Faris JA, eds. The Law of South Africa. 2nd ed. Durban: LexisNexis, 2008:para 30.

7. Medical Board of Australia v Dekker [2013] WASAT 182. http://www.austli.edu.au/au/cases/wa/ WASAT/2013/182.html (accessed 30 December 2015).

8. Jackson E. Medical Law: Text, Cases and Materials. 2nd ed. Oxford: Oxford University Press, 2010:126

9. Section 27(3) of the Constitution of the Republic of South Africa, 1996.

10. Section 5 of the National Health Act No. 61 of 2003.

11. Soobramoney v. Minister of Health, KwaZulu-Natal 1998 1 SA 765 (CC).

2. Ethical and Professional Rules of the Health Professions Council of South Africa. GN R717 in Government Gazette 29079 of 4 August 2006, as amended by GN R68 in Government Gazette 3182 of 2 February 2009: rule 21.

13. McQuoid-Mason DJ. The medical profession and medical practice. In: Joubert WA, Faris JA, eds. The Law of South Africa. 2nd ed. Durban: LexisNexis, 2008:para 44.

14. Wilsher v. Essex Area Health Authority [1987] 1 QB 730

Accepted 14 January 2016. 